\title{
The afterglow thermoluminescence band as an indicator of changes in the photorespiratory metabolism of the model legume Lotus japonicus
}

\author{
Margarita García-Calderón ${ }^{\mathrm{a}}$, Marco Betti ${ }^{\mathrm{a}}$, Antonio J. Márquez ${ }^{\mathrm{a}}$, José M. Ortega ${ }^{\mathrm{a}, \mathrm{b}}$ and \\ Mercedes Roncel ${ }^{a, b}$, * (iD \\ aDepartamento de Bioquímica Vegetal y Biología Molecular, Universidad de Sevilla, Sevilla, Spain \\ bInstituto de Bioquímica Vegetal y Fotosíntesis, Universidad de Sevilla y Consejo Superior de Investigaciones Científicas, Sevilla, Spain
}

\author{
Correspondence \\ ${ }^{*}$ Corresponding author, \\ e-mail: mroncel@us.es \\ Received 11 October 2018; \\ revised 12 December 2018 \\ doi:10.1111/ppl.12916
}

The afterglow (AG) luminescence is a delayed chlorophyll fluorescence emitted by the photosystem II that seems to reflect the level of assimilatory potential (NADPH+ATP) in chloroplast. In this work, the thermoluminescence (TL) emissions corresponding to the AG band were investigated in plants of the WT and the Ljgln2-2 photorespiratory mutant from Lotus japonicus grown under either photorespiratory (air) or non-photorespiratory (high concentration of $\mathrm{CO}_{2}$ ) conditions. TL glow curves obtained after two flashes induced the strongest overall TL emissions, which could be decomposed in two components: $\mathrm{B}$ band $\left(\mathrm{t}_{\max }=27-29^{\circ} \mathrm{C}\right)$ and $\mathrm{AG}$ band $\left(\mathrm{t}_{\max }=44-45^{\circ} \mathrm{C}\right)$. Under photorespiratory conditions, WT plants showed a ratio of 1.17 between the intensity of the $A G$ and $B$ bands $\left(I_{A G} / I_{B}\right)$. This ratio increased considerably under non-photorespiratory conditions (2.12). In contrast, mutant Ljgln2-2 plants grown under both conditions showed a high $\mathrm{I}_{\mathrm{AG}} / \mathrm{I}_{\mathrm{B}}$ ratio, similar to that of WT plants grown under non-photorespiratory conditions. In addition, high temperature thermoluminescence $(\mathrm{HTL})$ emissions associated to lipid peroxidation were also recorded. WT and Ljg/n2-2 mutant plants grown under photorespiratory conditions showed both a significant HTL band, which increased significantly under non-photorespiratory conditions. The results of this work indicate that changes in the amplitude of $\mathrm{I}_{\mathrm{AG}} / \mathrm{I}_{\mathrm{B}}$ ratio could be used as an in vivo indicator of alteration in the level of photorespiratory metabolism in L. japonicus chloroplasts. Moreover, the HTL results suggest that photorespiration plays some role in the protection of the chloroplast against lipid peroxidation.

\section{Introduction}

Photosynthetic luminescence is a delayed fluorescence emitted by photosystem II (PSII) that reflects the recombination of charge pairs separated by a prior irradiation and stabilized on carriers of the photosynthetic electron transfer chain. Luminescence decay phases can be better resolved by the thermoluminescence (TL) technique that records luminescence emission during the warming of a sample after an irradiation at a moderately low

Abbreviations - AG band, afterglow $\mathrm{TL}$ band; $\mathrm{B}$ band, $\mathrm{TL}$ band due to $\mathrm{S}_{2} / \mathrm{S}_{3} \mathrm{Q}_{\mathrm{B}}{ }^{-}$recombination; $\mathrm{DCMU}$, 3-(3,4-dichlorophenyl)-1,1-dimethylurea; $F R$, far red light; $H T L$, high temperature thermoluminescence; $I_{A G} / I_{B}$, ratio between the intensity of the $A G$ and $B$ bands; OEC, oxygen evolving complex; PR, photorespiration; PSI, photosystem I; PSII, photosystem II; $Q_{A}$ and $Q_{B}$, primary and secondary quinone electron acceptors of PSII; $S_{0 . . .0 .4}$, redox states of water oxidation complex; STL, standard thermoluminescence; TL, thermoluminescence; $t_{\max }$, temperature of the maximum of a TL band; $W T$, wild-type. 
non-freezing temperature (Miranda and Ducruet 1995, Ducruet 2003). After a sequence of short flashes, a so-called $B$ band of $T L$, peaking around $20-30^{\circ} \mathrm{C}$, is observed in both isolated photosynthetic membranes and intact systems, such as leaves and algae. This emission is due to the recombination of $\mathrm{S}_{2} / \mathrm{S}_{3} \mathrm{Q}_{\mathrm{B}}{ }^{-}$pairs, $\mathrm{Q}_{\mathrm{B}}$ being the secondary quinone acceptor and $S_{2} / S_{3}$ being the states of the oxygen-evolving complex (OEC) storing 2 and 3 positive charges (Rutherford et al. 1982). Another luminescence emission is the so-called afterglow (AG) band, peaking around $45^{\circ} \mathrm{C}$, which is usually observed in intact photosynthetic materials after far-red (FR > $700 \mathrm{~nm}$ ) irradiation (Bertsch and Azzi 1965, Miranda and Ducruet 1995, Roncel and Ortega 2005, Roncel et al. 2007, 2016).

The AG emission has been related to the cyclic transport of electrons around PSI because the complete suppression of this band has been observed by blocking the cyclic electron transfer fluxes (Nakamoto et al. 1988, Havaux et al. 2005). Thus, the FQR and NDH complexes, which both mediate the electron recycling from the donor side of PSI to the PQ pool during cyclic electron transport, are involved in the electron transfer leading to the AG signal (Havaux et al. 2005, Lintala et al. 2009). Moreover, it has been observed that short heat-treatments, in the same temperature range as the AG emission, trigger a PSI-driven electron flow from reducing components of unknown identity in the stroma towards the acceptor side of PSII (Havaux 1996). The reduction of $\mathrm{Q}_{\mathrm{B}}$ can also proceed in the dark by the chlororespiratory pathway, a process defined as a respiratory electron transport chain in interaction with photosynthetic electron transport involving both non-photochemical reduction and oxidation of plastoquinones (Bennoun 1982, Garab et al. 1989). All of the above supports the idea that $A G$ emission is due to the heat-induced reduction of $\mathrm{Q}_{B}$ by a stroma component and further recombination with $\mathrm{S}_{2} / \mathrm{S}_{3}$ states (Sundblad et al. 1988). Therefore, it is now accepted that AG emission does not originate from preformed charge pairs but reflects an electron transfer that occurs in the dark. Thus, it results from recombination of the $\mathrm{S}_{2} / \mathrm{S}_{3} \mathrm{Q}_{\mathrm{B}}{ }^{-}$states within PSII centers similarly to the $B$ band (Bertsch and Azzi 1965). The difference between $B$ and $A G$ emissions is apparently due to the $\mathrm{Q}_{B}$ reduction pathway.

This AG emission is often weaker or absent after white light (Palmqvist et al. 1986, Roncel and Ortega 2005, Roncel et al. 2007, 2016) but occurs in some material (Miranda and Ducruet 1995). However, this band has been observed under some metabolic conditions that slow down the use of photosynthetic energy, such as lack of $\mathrm{CO}_{2}$ or phosphorus (Mellvig and Tillberg 1986). The induction of the AG band by a single turnover flash has also been described in CAM-inducible species when CAM metabolism is activated (Krieger et al. 1998). Under these conditions, the intensity of the AG band $\left(\mathrm{I}_{\mathrm{AG}}\right)$ has been correlated with changes in the ratio of dihydroxy-acetone phosphate/phosphoglycerate (DHAP/PGA) which is an indicator of the energy status of the chloroplast. In fact, the intensity of the AG band is considered as an indicator of a high ATP/ADP and NADPH/NADP ${ }^{+}$ ratio in chloroplast (Krieger et al. 1998). A raise in the assimilatory potential (NADPH + ATP) due to stoma closure under slow dehydration has been also correlated with the strong increase in the AG band observed in wheat cultivar (Bürling et al. 2014). A decrease in the ratio between the intensity of the $A G$ and $B$ bands $\left(I_{A G} / I_{B}\right.$ ratio) observed in cold-sensitive pea varieties under cold conditions has also been correlated with a decrease in the assimilatory potential due to a cold-induced phosphate limitation in the chloroplast (Roman and Ducruet 2000).

Photorespiration (PR) is a light-induced biochemical process that takes place, along with photosynthesis, when the first enzyme in the photosynthetic $\mathrm{CO}_{2}$ fixation pathway, ribulose 1,5-bisphosphate (RuBP) carboxylase/oxygenase (Rubisco), oxygenates instead of carboxylates RuBP (Wingler et al. 2000, Peterhansel et al. 2010). The resulting products are one molecule of 3-phosphoglycerate (3PGA), which can be metabolized in the Calvin-Benson (CB) cycle, and one of 2-phosphoglycolate (2PG), a compound that is toxic to the plant as it inhibits the CB cycle enzyme activities (Farmer and Mueller 2013). 2PG is recycled in a complex pathway, the $\mathrm{C}_{2}$ cycle that encompasses three compartments: chloroplasts, mitochondria and peroxisomes (Hagemann et al. 2016). The cycle serves as a carbon recovery system by transforming 2PG into 3PGA, which goes back to the CB cycle (Wingler et al. 2000, Maurino and Peterhansel 2010).

$\mathrm{PR}$ is accompanied by $\mathrm{CO}_{2}$ and $\mathrm{NH}_{4}{ }^{+}$release. $\mathrm{NH}_{4}{ }^{+}$is produced as a result of the conversion of two molecules of glycine into one molecule of serine in a reaction catalyzed by an enzymatic complex in the mitochondria, which forms part of a more complex process called the photorespiratory nitrogen cycle (Maurino and Peterhansel 2010). It was initially thought that cytosolic glutamine synthetase $\left(\mathrm{GS}_{1}\right)$ could be responsible for photorespiratory ammonium assimilation. However, the isolation in barley of photorespiratory mutants specifically deficient in plastidic GS showed that the chloroplastic form of glutamine synthetase $\left(\mathrm{GS}_{2}\right)$ was in fact responsible for this process (Wallsgrove et al. 1987, Keys 2006).

The first GS photorespiratory mutants isolated from legume plants were identified several years ago in our 
laboratory from the model legume L. japonicus (Orea et al. 2002, Márquez et al. 2005). These mutants have been substantially characterized at the molecular and physiological levels (Orea et al. 2002, Márquez et al. 2005, Betti et al. 2006, Pérez-Delgado et al. 2013, Betti et al. 2014, Pérez-Delgado et al. 2016). One of the mutants, named Ljg/n2-2, is deficient in plastidic GS $\left(\mathrm{GS}_{2}\right)$ but has normal levels of cytosolic GS $\left(\mathrm{GS}_{1}\right)$ (Orea et al. 2002, Márquez et al. 2005, Betti et al. 2012). This mutant presents a single-point allelic mutation $\mathrm{L} 278 \mathrm{H}$ that affected the stability of the $\mathrm{GS}_{2}$ polypeptide. A complete lack of $\mathrm{GS}_{2}$ protein was observed in leaves, roots and nodules of the Ljg/n2-2 mutant (Betti et al. 2006, García-Calderón et al. 2012). The Ljgln2-2 mutant is able to grow in a similar manner to the wild-type (WT) at high $\mathrm{CO}_{2}$ conditions that suppress PR. However, it accumulates high levels of $\mathrm{NH}_{4}{ }^{+}$ when transferred from high $\mathrm{CO}_{2}$ to air conditions, as a consequence of the activation of PR and the lack of $\mathrm{GS}_{2}$ (Orea et al. 2002, Pérez-Delgado et al. 2013, Betti et al. 2014, Pérez-Delgado et al. 2015). Photorespiratory ammonium accumulation was also shown previously in barley $\mathrm{GS}_{2}$ mutants (Wallsgrove et al. 1987) and in $\mathrm{GS}_{2}$-antisense oilseed rape lines (Husted et al. 2002).

$\mathrm{PR}$ is regarded as an energetically costly sequence of reactions where both energy (ATP) and reducing (NADPH) equivalents are required, in great part due to the retrieval of $\mathrm{CO}_{2}$ and $\mathrm{NH}_{4}{ }^{+}$, which are released during the glycine cleavage reaction in mitochondria. The $\mathrm{CO}_{2}$ re-fixation by Rubisco and further assimilation through the $\mathrm{CB}$ cycle requires both reducing and phosphorylating potentials (NADPH and ATP). The ammonium fixation in the chloroplast by the GS/GOGAT system occurs at the expense of reduced ferredoxin and ATP (Peterhansel et al. 2010, Hagemann et al. 2016). Thus, the AG band might be regarded as an indicator of changes in the levels of ATP and/or NADPH induced by alterations in the photorespiratory metabolism.

In this work, we have analyzed the changes observed in the TL bands in L. japonicus plants cultivated under high $\mathrm{CO}_{2}$ conditions that suppress PR and under air conditions that permit a normal flux through the PR pathway. We included in our study the Ljg/n2-2 mutant deficient in $\mathrm{GS}_{2}$ activity that is required for photorespiratory ammonium reassimilation in the chloroplasts and consequently impaired in the photorespiratory cycle (Orea et al. 2002, Pérez-Delgado et al. 2013, Betti et al. 2014, Pérez-Delgado et al. 2015). The results obtained in this work indicate that the $\mathrm{I}_{\mathrm{AG}} / \mathrm{I}_{\mathrm{B}}$ ratio and the level of lipid peroxidation significantly increase under conditions that suppress PR.

\section{Materials and methods}

\section{Plant material and growth conditions}

Lotus japonicus (Regel) Larsen cv. Gifu were initially obtained by Prof. Jens Stougaard (University of Aarhus, Denmark) and then self-propagated at the University of Seville. The Ljgln2-2 mutant was isolated from a photorespiratory mutant screen as described previously (Orea et al. 2002, Márquez et al. 2005). The mutant progeny of two consecutive backcrosses into the WT background were used. WT and mutant seeds were scarified and surface-sterilized, then germinated in $1 \%$ agar in Petri dishes and transferred to pots using vermiculite as solid support. Five seedlings were planted in each pot and grown during 35 days in Sanyo (Osaka, Japon) or Ibercex (Madrid, Spain) growth chambers under $16 / 8 \mathrm{~h}$ day/night cycles $\left(20 / 18^{\circ} \mathrm{C}\right)$, with a photosynthetic flux density of $250 \mu \mathrm{mol} \mathrm{m}^{-2} \mathrm{~s}^{-1}$ and a constant humidity of $70 \%$. The experiments described in this work were carried out using L. japonicus plants (WT and Ljgln2-2 mutant) grown under photorespiratory conditions (air, $0.04 \% \mathrm{v} / \mathrm{v} \mathrm{CO}_{2}$ ) or photorespiratory-suppressed conditions (high $\mathrm{CO}_{2}, 0.7 \% \mathrm{v} / \mathrm{v} \mathrm{CO}_{2}$ by injection of $\mathrm{CO}_{2}$ ). The plants were watered with Hornum nutrient solution (Handberg and Stougaard 1992).

\section{Thermoluminescence}

Thermoluminescence (TL) glow curves of L. japonicus plants were obtained using a home-built apparatus (University of Seville-CSIC, Spain) designed by $\mathrm{Dr}$ Ducruet (Université Paris-Sud-Orsay, Orsay, France) for luminescence detection from 1 to $70^{\circ} \mathrm{C}$ (standard thermoluminescence, STL) and from 10 to $160^{\circ} \mathrm{C}$ (high temperature thermoluminescence, HTL). A detailed description of the system can be obtained elsewhere (Ducruet 2003, Zurita et al. 2005, Sajnani et al. 2007, Guerrero et al. 2014, Repetto et al. 2015). Data acquisition, signal analysis and graphical simulation were performed as previously described (Ducruet 2003, Zurita et al. 2005). Before each TL experiment, the plants were kept under weak white light. Typically, for STL measurements, the leaf-disc was dark-incubated for 2 min at $20^{\circ} \mathrm{C}$, then cooled at $1^{\circ} \mathrm{C}$ for $1 \mathrm{~min}$ and illuminated at the end of this period with saturating single turn-over flashes (separated by $1 \mathrm{~s}$ ) of white light (Walz) through an optic fiber. Luminescence emission was immediately recorded while warming the sample from 0 to $70^{\circ} \mathrm{C}$ at a heating rate of $0.5^{\circ} \mathrm{C} \mathrm{s}^{-1}$. In some experiments, before recording the luminescence emissions, FR illumination was performed by a tungsten lamp through a $720 \mathrm{~nm}$ interference filter $\left(4 \mu \mathrm{mol} \mathrm{m}{ }^{-2} \mathrm{~s}^{-1}\right)$. TL glow curves were decomposed into elementary bands by mathematical 
simulation and analyzed as previously described by Ducruet (2003). Additionally, HTL measurements were carried out with the same setup using a similar protocol, but the leaf disc was dark-incubated for $10 \mathrm{~min}$ at $20^{\circ} \mathrm{C}$ and cooled to $10^{\circ} \mathrm{C}$ for $1 \mathrm{~min}$. Luminescence emission was then recorded while warming samples from 10 to $160^{\circ} \mathrm{C}$ at a heating rate of $0.1^{\circ} \mathrm{C} \mathrm{s}^{-1} \cdot \mathrm{N}_{2}$ gas was flushed on the sample during HTL experiments in order to desiccate samples and prevents any oxidation induced by high temperatures. The TL experiments were repeated seven times using different plants, except those corresponding to Fig. 2 that had five replicates. The experiments shown in Figs $1-5$ are representative examples of all repetitions.

\section{Results}

\section{STL analysis of WT L. japonicus plants}

The main objective of this work was to determine if there is a relationship between the levels of PR and the intensity of the AG band in L. japonicus plants. Initially, we have characterized the most relevant TL bands detected in vivo in L. japonicus plants grown under standard air conditions. To our knowledge, no TL studies

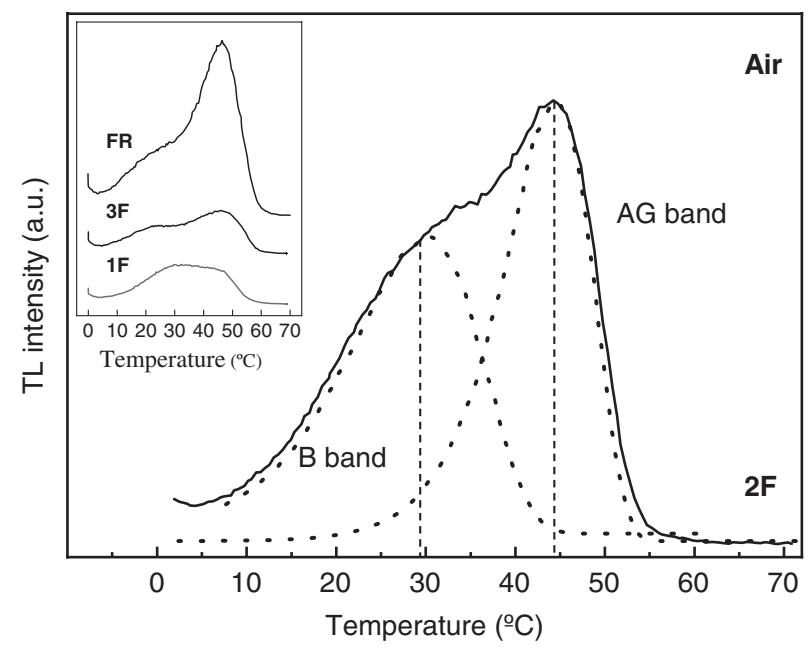

Fig. 1. Thermoluminescence glow curves from leaves of $L$. japonicus plants grown in air recorded after a series of single turn-over flashes or under FR light (indicated on each curve). Leaf segments were dark-adapted for 2 min at $20^{\circ} \mathrm{C}$, and subsequently cooled to $1^{\circ} \mathrm{C}$ during $1 \mathrm{~min}$. One, two and three flashes (1F, $2 \mathrm{~F}$ and $3 \mathrm{~F}$ ) were given at the end of this period as indicated for each curve. For FR curve, leaf segments were dark-adapted for $2 \mathrm{~min}$ at $20^{\circ} \mathrm{C}$, then irradiated $3 \mathrm{~min}$ with $720 \mathrm{~nm}$ light at $20^{\circ} \mathrm{C}$ and subsequently cooled to $1^{\circ} \mathrm{C}$ during $1 \mathrm{~min}$. Two flashes were given at the end of this period and TL curve recorded. TL curve obtained after $2 \mathrm{~F}$ were fitted by two components. The dotted lines represent the simulation components corresponding to the best fit (see section Materials and methods). The dashed lines indicate the temperature maximum of TL bands. Inset: TL signal recorded after one flash (1F), three flashes (3F) and FR light.

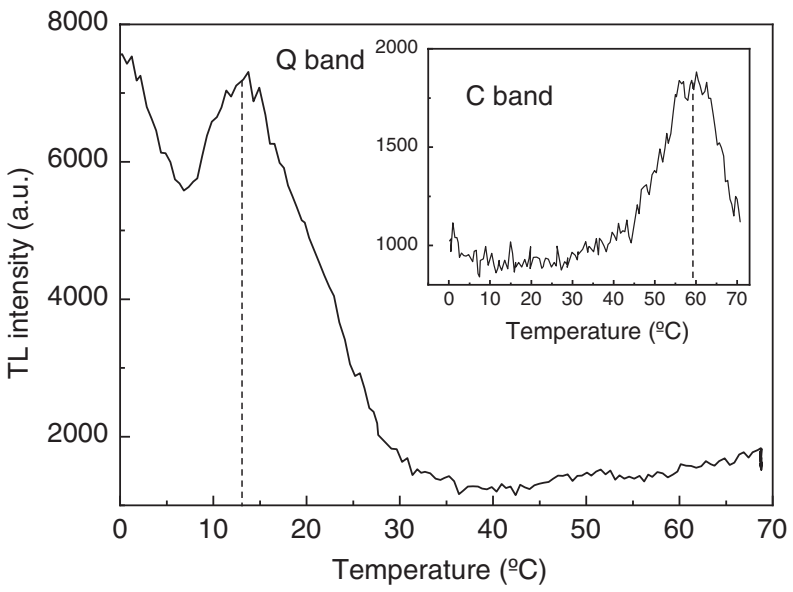

Fig. 2. Thermoluminescence glow curves from leaves of $L$. japonicus previously incubated in the presence of DCMU. Dark-adapted leaf segments were incubated in the dark at room temperature in $50 \mu \mathrm{M} \mathrm{DCMU}$ in water solution. One flash was given at the end of this period and $\mathrm{TL}$ curve recorded. Inset: TL curve recorded after $15 \mathrm{~min}$ of dark-incubation in non-flashed untreated leaves. This curve was amplified 10 times for comparison. The dashed lines indicate the temperature maximum of TL bands.

have been previously carried out in this species. Excitation of dark-adapted leaf discs with a series of white light saturating single turn-over flashes $(1 \mathrm{~F}, 2 \mathrm{~F}$ and $3 \mathrm{~F})$ at $1^{\circ} \mathrm{C}$ induced the appearance of two overlapping TL glow curves different in the temperature of the maximum $\left(\mathrm{t}_{\max }\right)$ and signal intensity (Fig. 1). The emission curve obtained after two flashes produced a maximal overall emission ( $2 \mathrm{~F}$ in Fig. 1). The decomposition analysis of this emission curve is also shown ( $2 \mathrm{~F}$ dotted lines in Fig. 1). The first component can be assigned to the well-known $\mathrm{TL}$ $B$ band originating from the recombination of $\mathrm{S}_{3} / \mathrm{S}_{2} \mathrm{Q}_{\mathrm{B}}{ }^{-}$ charge pairs in PSII (Rutherford et al. 1982). An average value of $28.8^{\circ} \mathrm{C}$ for $t_{\max }$ and a signal contribution of $46 \%$ were obtained for this band (Table 1 ). The second TL component appearing at higher temperature can be tentatively assigned to an AG band. An average value of $t_{\max }$ of $44.4^{\circ} \mathrm{C}$ and a signal contribution of $54 \%$ were obtained for the AG band (Table 1). In order to quantify the relative variation of the AG band, its integrated area $\left(I_{A G}\right)$ was always related to the integrated area of the $B$ band $\left(I_{B}\right): I_{A G} / I_{B}$. The $I_{A G} / I_{B}$ ratio calculated for $W T$ $L$. japonicus plants grown under standard air conditions was 1.17 (Table 1).

To confirm that the TL band appearing around $45^{\circ} \mathrm{C}$ in $L$. japonicus plants after white light flash excitation can be identified as a typical AG band (normally induced by FR light), we have also performed TL measurements replacing white light flash excitation by $720 \mathrm{~nm}$ (FR) monochromatic continuous light excitation (Fig. 1, inset FR). This type of illumination 
generated a prominent $45^{\circ} \mathrm{C}$-band on which a weaker $\mathrm{B}$ band appeared as a shoulder. This FR light, by predominantly exciting PSI, over-oxidizes the PQ pool, increases the stroma reduction and, by weakly exciting PSII, generates silent $S_{2} / S_{3} Q_{B}$ centers. These centers produce the $\mathrm{AG}$ band when they are converted into the luminescence-emitting $\mathrm{S}_{2} / \mathrm{S}_{3} \mathrm{Q}_{\mathrm{B}}{ }^{-}$centers via cyclic pathways from stroma reductants (Sundblad et al. 1988, Miranda and Ducruet 1995). This can explain the increase of the AG band after FR excitation. It is clearly established that only PSII centres initially in the states $\mathrm{S}_{0} / \mathrm{S}_{1} \mathrm{Q}_{\mathrm{B}}{ }^{-}$will be able to produce, after two flashes, the luminescence emitting states $S_{2} / S_{3} Q_{B}{ }^{-}$responsible for $B$ band emission (Rutherford et al. 1982). The above described results support that the $44.4^{\circ} \mathrm{C}$ band observed in L. japonicus leaves after excitation with white light flashes corresponds to the same recombination reaction originating the FR-induced AG band described by Miranda and Ducruet (1995).

We have also studied recombination reactions involving $Q_{A}$. TL emissions after flashing leaves discs of WT L. japonicus plants previously incubated in the presence of DCMU are shown in Fig. 2 (Q band). In these samples after one flash of white light, the B and AG bands completely disappeared and a different TL band was detected: the $\mathrm{Q}$ band corresponding to $\mathrm{S}_{2} \mathrm{Q}_{\mathrm{A}}{ }^{-}$recombination (Demeter and Govindjee 1989, Ducruet 2003, Ducruet and Vass 2009). An average value of $13.4^{\circ} \mathrm{C}$ for $t_{\max }$ of this band was determined. In the absence of any previous illumination (Fig. 2, inset), untreated leaf discs exhibited upon warming a $\mathrm{C}$ band with TL emission peaking at $59.8^{\circ} \mathrm{C}$. The intensity of this dark-stable band, which is the result of $\mathrm{Tyr}_{\mathrm{D}}{ }^{+} \mathrm{Q}_{\mathrm{A}}{ }^{-}$recombination (Johnson et al. 1994), is weak compared with those of the B, AG and $\mathrm{Q}$ bands which originate from the recombination of charge pairs created by illumination (Sajnani et al. 2007).

It is known that high $\mathrm{CO}_{2}$ concentrations suppress the photorespiratory process (Urban 2003). In this work, we have performed TL measurements in WT $L$. japonicus plants grown under high concentration of $\mathrm{CO}_{2}$ in order to analyze the physiological response to non-photorespiratory conditions (Fig. 3). Excitation of dark-adapted leaf discs of WT L. japonicus plants grown under high $\mathrm{CO}_{2}$ conditions with a series of white light flashes showed the same oscillation pattern for TL emissions than plants growing in air (data not shown). The overall TL emissions reached a maximum after two flashes and the decomposition analysis of this emission curve is shown (Fig. 3, dotted lines). Average values of 27.7 and $44^{\circ} \mathrm{C}$ for $\mathrm{t}_{\max }$, and of 32 and $68 \%$ for signal contributions of $\mathrm{B}$ and $\mathrm{AG}$ bands were obtained, respectively (Table 1). Thus, the main effect observed for the plants growing under high $\mathrm{CO}_{2}$ concentration was a

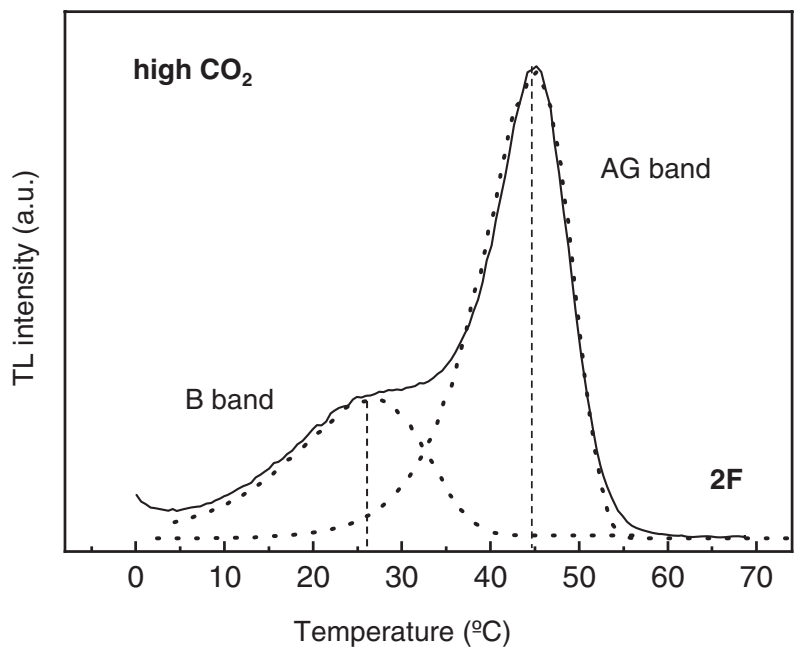

Fig. 3. Thermoluminescence glow curves from leaves of $L$. japonicus plants grown under high $\mathrm{CO}_{2}$ concentration after two single turn-over flashes (2F). Leaf segments were dark-adapted for $2 \mathrm{~min}$ at $20^{\circ} \mathrm{C}$, and subsequently cooled to $1^{\circ} \mathrm{C}$ during $1 \mathrm{~min}$. Two flashes were given at the end of this period and the TL curve recorded. The curve obtained was fitted by two components. The dotted lines represent the simulation components corresponding to the best fit. The dashed lines indicate the temperature maximum of $\mathrm{TL}$ bands.

significant increase (about 15\%) of the contribution of the AG band to the total TL intensity, and consequently of the $I_{A G} / I_{B}$ ratio. In fact, the $I_{A G} / I_{B}$ ratio obtained for WT plants under high $\mathrm{CO}_{2}$ conditions was 2.12, a value significantly higher than that obtained under air conditions (1.17; Table 1). No significant changes were detected in $t_{\max }$ values of $B$ and AG bands for either photorespiratory and non-photorespiratory conditions (Figs 1 and 3 and Table 1).

\section{STL analysis of LjgIn2-2 photorespiratory mutant plants}

We have also analyzed TL emission bands of Ljg/n2-2 mutant plants grown under standard air (Fig. 4, air) and high $\mathrm{CO}_{2}$ concentration (Fig. 4, high $\mathrm{CO}_{2}$ ). Fig. 4 shows only the emission curves obtained in plants after two flashes $(2 \mathrm{~F})$, which produced the maximal overall emissions. These curves could be well simulated by two decomposition components, B and AG bands, with differences in the $t_{\max }$ and contributions to the total signal intensity (Table 1). Ljg/n2-2 mutant plants did not show significant differences in B and AG bands $\left(t_{\max }\right.$ and intensity contributions) when maintained either on high $\mathrm{CO}_{2}$ or air (Fig. 4 and Table 1). The intensities contribution values obtained were similar, $34.8 \%$ and $35.9 \%$ for $\mathrm{B}$ band and $65.1 \%$ and $64.1 \%$ for $\mathrm{AG}$ band, in air and high $\mathrm{CO}_{2}$ conditions, respectively (Table 1 ). The $\mathrm{I}_{\mathrm{AG}} / \mathrm{I}_{\mathrm{B}}$ ratio obtained from $\mathrm{Ljg} / \mathrm{n} 2-2$ plants under air and 

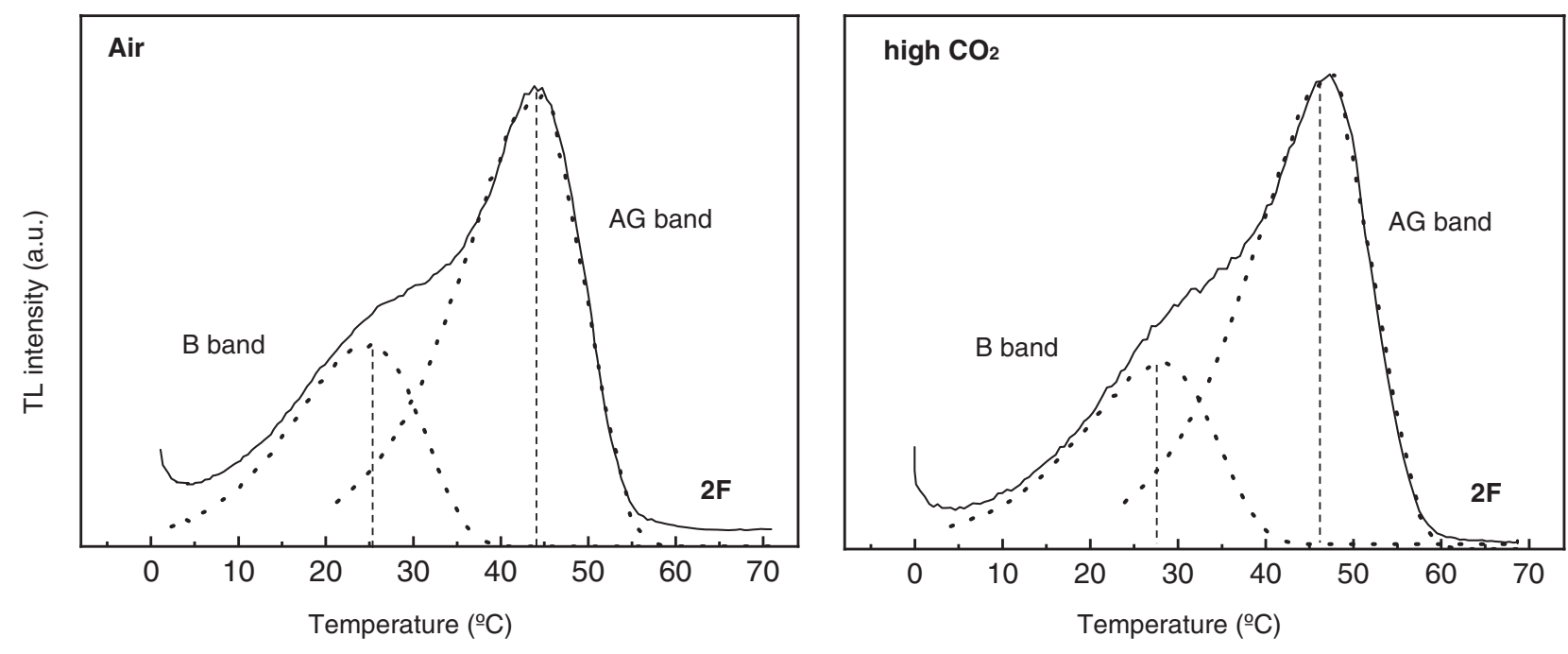

Fig. 4. Thermoluminescence glow curves from leaves of $L j g / n 2-2 \mathrm{~L}$. japonicus mutant plants grown under air and high $\mathrm{CO}_{2}$ conditions. $\mathrm{Curves}$ were recorded from leaf segments dark-adapted for $2 \mathrm{~min}$ at $20^{\circ} \mathrm{C}$ and subsequently cooled to $1^{\circ} \mathrm{C}$ during $1 \mathrm{~min}$. Two flashes $(2 \mathrm{~F})$ were given at the end of this period as indicated on each curve. TL curves obtained were fitted by two components. The dotted lines represent the simulation components corresponding to the best fit. The dashed lines indicate the temperature maximum of TL bands.

Table 1. Thermoluminescence band emissions of WT and Ljgln2-2 L. japonicus plants under air or high concentration of $\mathrm{CO}_{2}$.

\begin{tabular}{|c|c|c|c|c|c|c|}
\hline \multirow[b]{2}{*}{ Genotype } & \multirow[b]{2}{*}{ Conditions } & \multicolumn{2}{|c|}{$\mathrm{B}$ band } & \multicolumn{2}{|c|}{ AG band } & \multirow[b]{2}{*}{$\mathrm{I}_{\mathrm{AG}} / \mathrm{I}_{\mathrm{B}}$ ratio } \\
\hline & & $\mathrm{t}_{\max }\left({ }^{\circ} \mathrm{C}\right)$ & Signal contribution (\%) & $\mathrm{t}_{\max }\left({ }^{\circ} \mathrm{C}\right)$ & Signal contribution (\%) & \\
\hline \multirow[t]{2}{*}{ Wild-type } & Air & $28.8 \pm 0.8$ & $46.0 \pm 1.2$ & $44.4 \pm 0.9$ & $54.0 \pm 1.2$ & $1.17 \pm 0.06$ \\
\hline & $\mathrm{CO}_{2}$ & $27.7 \pm 1.0$ & $32.0 \pm 1.4$ & $44.0 \pm 0.8$ & $68.0 \pm 1.3$ & $2.12 \pm 0.12$ \\
\hline \multirow{2}{*}{ Ljgln2-2 } & Air & $26.6 \pm 0.7$ & $34.8 \pm 0.9$ & $44.6 \pm 0.7$ & $65.1 \pm 0.9$ & $1.87 \pm 0.07$ \\
\hline & $\mathrm{CO}_{2}$ & $28.3 \pm 0.9$ & $35.9 \pm 1.2$ & $44.8 \pm 0.8$ & $64.1 \pm 1.2$ & $1.79 \pm 0.09$ \\
\hline
\end{tabular}

high $\mathrm{CO}_{2}$ conditions were 1.87 and 1.79 , respectively (Table 1). It should be noted that the $I_{A G} / I_{B}$ ratio in the mutant under air conditions (1.87) was significantly higher than that obtained for the WT plants under the same conditions (1.17).

\section{HTL analysis of WT and Ljgln2-2 mutant plants}

We also studied the levels of lipid peroxidation in WT and Ljg/n 2-2 mutant plants grown under both photorespiratory and non-photorespiratory conditions. The level of lipid peroxidation in photosynthetic membranes can be measured by the high temperature TL technique (HTL; see section Materials and methods and Vavilin and Ducruet 1998, Ducruet and Vavilin 1999, Vavilin et al. 2002, Roncel et al. 2007).

Fig. 5 displays the overall HTL emissions from 10 to $160^{\circ} \mathrm{C}$ in leaves of WT and Ljg/n2-2 mutant plants grown under air and high $\mathrm{CO}_{2}$ conditions. The HTL emissions obtained from WT and Ljg/n2-2 mutant plants under air conditions (Fig. 5, traces 1 and 3, respectively) showed the appearance of an important HTL2 band $\left(\mathrm{t}_{\max }\right.$ of $128-133^{\circ} \mathrm{C}$ ), whose intensity in $\mathrm{Ljg} / \mathrm{n} 2-2$ mutant plants was slightly higher (around 15\%). The same HTL2 band

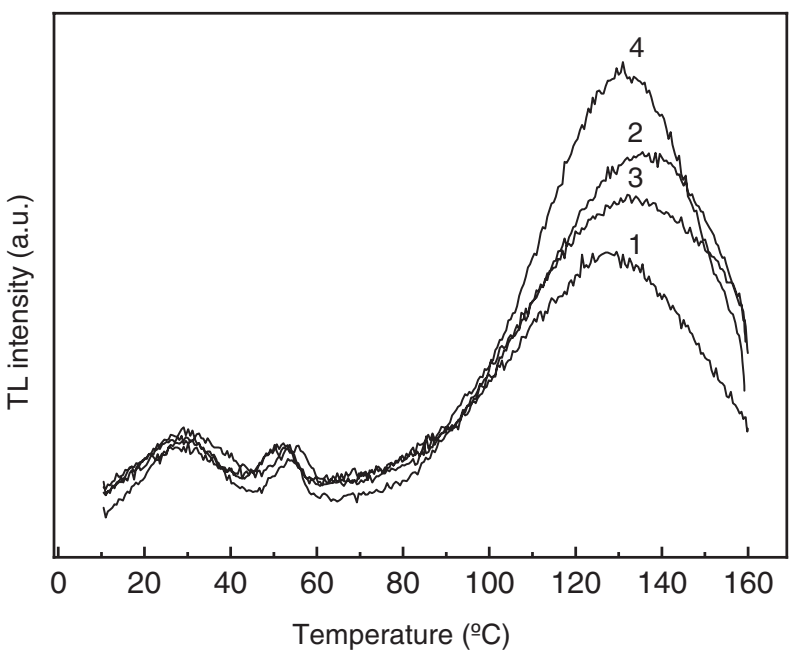

Fig. 5. High-temperature thermoluminescence from leaves of WT and Ljgln2-2 L. japonicus plants grown under air or high $\mathrm{CO}_{2}$ conditions. Samples were dark-adapted for $1 \mathrm{~min}$ at $10^{\circ} \mathrm{C}$ and heated with a slow warming rate of $0.1^{\circ} \mathrm{C} \mathrm{s}^{-1}$ from 10 to $160^{\circ} \mathrm{C}$ without light excitation. WT and Ljgln 2-2 plants were growing under air (traces 1 and 3, respectively) or under high $\mathrm{CO}_{2}$ conditions (traces 2 and 4 , respectively). In order to desiccate the samples and prevent any oxidation induced by high temperature, leaves were flushed with nitrogen during the HTL experiments. 
$\left(\mathrm{t}_{\max }\right.$ of $130-135^{\circ} \mathrm{C}$ ) emerged in both WT and Ljg/n2-2 mutant plants grown under high $\mathrm{CO}_{2}$ conditions, but with a significant higher intensity (Fig. 5, traces 2 and 4, respectively). Therefore, we can consider that the greater intensity of the HTL2 band under high $\mathrm{CO}_{2}$ in comparison with air conditions, both in WT and in Ljg/n2-2 mutant (Fig. 5), is indicative of a higher peroxidation of chloroplast lipids when PR is suppressed.

\section{Discussion}

The aim of this work was to study if there is any correlation between the intensity of the AG TL band and the photorespiratory metabolism in L. japonicus plants. As already mentioned, the intensity of the AG TL emission depends on the 'assimilatory potential' that is the concentration of NADPH and ATP in the stroma (Gerst et al. 1994, Krieger et al. 1998). Because PR is a process that requires extra energy cost, blocking it using a high $\mathrm{CO}_{2}$ environment will allow us to check whether its suppression, and consequently the increase of the assimilatory potential, will induce an increase in AG band intensity.

\section{The high intensity of AG band in L. japonicus}

The data presented in this work show the appearance of a TL band with a maximum emission at $45^{\circ} \mathrm{C}$ induced in leaves of $L$. japonicus by two flashes (Fig. 1) or after FR illumination (Fig. 1, inset). We propose that this band corresponds to the so-called afterglow (AG) band. It corresponds to the fraction of PSII centers in the $S_{2 / 3} Q_{B}$ non-radiative state immediately after pre-illumination, in which the arrival of an electron transferred from stroma along cyclic/chlororespiratory pathway(s) produces the $\mathrm{S}_{2 / 3} \mathrm{Q}_{\mathrm{B}}{ }^{-}$radiative state that emits luminescence (Sundblad et al. 1988).

An $\mathrm{I}_{\mathrm{AG}} / \mathrm{I}_{\mathrm{B}}$ ratio of 1.17 has been determined in $L$. japonicus plants grown under air conditions (Table 1). As already mentioned, the intensity of AG emission is considered as an in vivo indicator of the assimilatory potential (NADPH + ATP) when it is inducible by a white light illumination in green algae (Mellvig and Tillberg 1986, Palmqvist et al. 1986, Sundblad et al. 1986) or flash excitation in plants (Miranda and Ducruet 1995, Krieger et al. 1998). The assimilatory potential, which is also dependent on the cellular energetic status, has also been correlated to the dihydroxyacetone-P/PGA ratio (Heber et al. 1986). An increase in the flash-induced AG band has been observed in CAM plants during the phases of the diurnal cycle corresponding to a high dihydroxyacetone-P/PGA ratio and consequently a strong phosphorylation and reduction potential
(Krieger et al. 1998). A decrease of the flash-induced AG emission in cold-sensitive pea varieties has been also observed under cold conditions. It correlated with a decrease of the assimilatory potential, which can be explained as a cold-induced phosphate limitation in the chloroplast (Roman and Ducruet 2000).

The high value of the intensity of AG band induced by two flashes in control air conditions observed in this work seems to demonstrate that a metabolic state (a high level of NADPH/ATP) leading to this emission may arise spontaneously in non-stressed $L$. japonicus leaves. It has been described that temperate annual legume species as L. japonicus carry out most of their nitrate assimilation in the root (Andrews 1986, Woodall and Forde 1996, Márquez et al. 2005). Because the assimilation of nitrate in L. japonicus is a major drainage of assimilation power process (Márquez et al. 2005), the high level in AG band intensity could correspond to the lack of nitrate assimilation in the leaves of this plant. However, more experiments are needed to confirm this proposal.

\section{The intensity of AG band as indicator of changes in the photorespiratory metabolism}

PR is an energetically costly process where both energy (ATP) and reducing equivalent (NADPH) are required (Wingler et al. 2000, Hagemann et al. 2016). Therefore, under conditions in which the PR is suppressed (high concentration of $\mathrm{CO}_{2}$ ), NADPH and ATP can accumulate, raising the assimilatory potential. The very significant increase in $\mathrm{I}_{\mathrm{AG}} / \mathrm{I}_{\mathrm{B}}$ value observed in plants grown under high $\mathrm{CO}_{2}$ conditions (2.12) in comparison with standard air conditions (1.17) may be due to this greater availability of NADPH and/or ATP (Fig. 3 and Table 1). An increase of the assimilatory potential in the stroma of plants grown at high $\mathrm{CO}_{2}$ concentration due to the PR suppression has already been described (Urban 2003). Therefore, the intensity of the AG band might be regarded as an indicator of this extra ATP and/or NADPH when PR is inactive.

At high $\mathrm{CO}_{2}$ concentration, there could be other metabolic processes apart from impairment of the PR that generate an increase in assimilatory potential. However, the availability of a photorespiratory mutant ( $\mathrm{Ljg} / \mathrm{n} 2-2)$ deficient in plastidic glutamine synthetase enzyme $\left(\mathrm{GS}_{2}\right)$ allowed us to confirm the relationship between the increasing AG band intensity and the PR blocking at a high $\mathrm{CO}_{2}$ concentration. Ljg/n2-2 mutant plants grown under air conditions showed a high $\mathrm{I}_{\mathrm{AG}} / \mathrm{I}_{\mathrm{B}}$ ratio (1.87), similar to that obtained for WT plants grown under high $\mathrm{CO}_{2}$ conditions (Table 1). Therefore, the excess of assimilatory potential due to either the impairment of the photorespiratory pathway in WT plants under high $\mathrm{CO}_{2}$ 
conditions or in Ljg/n2-2 mutant plants due to photorespiratory mutation could be the responsible for the significant increase of AG band intensity in L. japonicus plants.

\section{Photorespiration seems to protect chloroplasts against lipid peroxidation}

The HTL experiments of this work have shown a significant lipid peroxidation level in both WT and Ljg/n2-2 plants either in high $\mathrm{CO}_{2}$ or air conditions (Fig. 5). The broad HTL band emission obtained in both conditions (centered near $130^{\circ} \mathrm{C}$ and known as the HTL2 band) is indicative of oxidative damage (Havaux and Niyogi 1999, Vavilin et al. 2002). In fact, the amplitude of this band has been well correlated with the accumulation of malondialdehyde, an indicator of lipid peroxidation in standard chemical tests (Vavilin and Ducruet 1998, Vavilin et al. 2002).

As already mentioned, temperate annual legume species as $L$. japonicus carries out most of their nitrate assimilation in the root (Andrews 1986, Woodall and Forde 1996, Márquez et al. 2005). Thus a high $\mathrm{NADPH} / \mathrm{NADP}^{+}$ratio must be present in the leaves of these legume species when they are grown in air. Consequently, a decrease of the amount of oxidized $\mathrm{NADP}^{+}$available as electron acceptor could result in an over-reduction of the photosynthetic electron transport chain (Kozaki and Takeba 1996, Ahmad et al. 2008). Under such conditions, ferredoxin is over-reduced and electrons originating from water oxidation in PSII may be transferred from PSI to oxygen to form superoxide radicals $\left(\mathrm{O}_{2} \cdot{ }^{-}\right)$by the process called Mehler reaction and subsequently produce hydrogen peroxide $\left(\mathrm{H}_{2} \mathrm{O}_{2}\right)$ via $\mathrm{O}_{2} \cdot{ }^{-}$(Asada 2006, Ahmad et al. 2008). These reactive oxygen species (ROS), $\mathrm{O}_{2}{ }^{--}$and $\mathrm{H}_{2} \mathrm{O}_{2}$, can initiate the lipid peroxidation (Triantaphylidès et al. 2008, Farmer and Mueller 2013) in the chloroplast of L. japonicus.

On the other hand, the HTL experiments of this work have also shown a significant increase in lipid peroxidation in chloroplasts when PR is impaired, i.e. at high $\mathrm{CO}_{2}$ concentration and/or in the Ljg/n2-2 mutant. Noteworthy, higher levels of HTL signals were detected in high $\mathrm{CO}_{2}$ conditions compared to air, both in the WT and the Ljg/n2-2 mutant, and also in the mutant plants compared to the WT on each of these conditions (Fig. 5). These results might be explained by assuming that PR blocking increases ROS production as a result of higher levels of NADPH and ATP. A contribution of PR metabolism in the protection from photoinhibition and the dissipation of excess excitation energy has been proposed (Kozaki and Takeba 1996, Wingler et al. 2000, Takahashi et al. 2007, Peterhansel et al. 2010, Takahashi and Badger
2011). It is considered that consumption of photochemical energy, stored as ATP and NADPH, through PR helps preventing the overreduction of the photosynthetic electron transport, and thus protects against the photooxidative damage by ROS. PR, as a defense mechanism from photoinhibition, has also been shown in transgenic tobacco plants overexpressing the plastidic $\mathrm{GS}_{2}$ enzyme (Kozaki and Takeba 1996). These authors proposed that PR has a protective function against photooxidation, possibly via the up-regulation of glutamine synthetase $\left(\mathrm{GS}_{2}\right)$ to recycle ammonia, diminishing photooxidation and photoinhibition. Recently, it has been proposed that PR has a specific direct effect on electron transport, in addition to preventing its over-reduction by the consumption of NADPH and ATP (Messant et al. 2018). These authors suggested that modification of the redox properties of $\mathrm{Q}_{\mathrm{A}}$ by the photorespiratory metabolite glycolate favors the direct charge recombination pathway between $\mathrm{P}_{680}+$ and $\mathrm{Q}_{\mathrm{A}}{ }^{-}$and, in that way, lowers ${ }^{1} \mathrm{O}_{2}$ generation in the reaction center of PSII.

\section{Conclusions}

The results of this work have shown that the absence of a functional PR pathway in plants of $L$. japonicus under high $\mathrm{CO}_{2}$ conditions led to a significant increase in the $\mathrm{I}_{\mathrm{AG}} / \mathrm{I}_{\mathrm{B}}$ ratio. A greater availability of $\mathrm{NADPH}$ and ATP could be the reason (Wingler et al. 2000, Urban 2003). Our results show that the AG band could be regarded as an indicator of this extra ATP and/or NADPH in the plant under non-photorespiratory conditions. Thus, TL proves to be a useful technique to study changes in the photorespiratory metabolism in vivo in L. japonicus plants. Moreover, the HTL results confirm that PR plays a role in the protection of the chloroplast against lipid peroxidation.

\section{Author contributions}

M.G-C., J.M.O., A.J.M. and M.R. conceived and designed experiments. M.G-C. and M.R. performed the experiments. M.G-C., J.M.O. and M.R. wrote the manuscript. All the authors contributed to the discussion, correction and approved the final manuscript.

Acknowledgements - We acknowledge financial support given by the Spanish Ministry of Economy and Competitiveness (BIO2015-64169, BIO2013-43556 and AGL2014-54413-R) and the Andalusian Government (PAIDI BIO-022 and BIO-163). All these grants were partially financed by the EU FEDER Program. We would like to thank Dr Anna Lindahl for critically reading the manuscript. 


\section{References}

Ahmad P, Sarwat M, Sharma S (2008) Reactive oxygen species, antioxidants and signaling in plants. J Plant Biol 51: $167-173$

Andrews M (1986) The partitioning of nitrate assimilation between root and shoot of higher plants. Plant Cell Environ 9: 511-519

Asada K (2006) Production and scavenging of reactive oxygen species in chloroplasts and teir functions. Plant Physiol 141: 391-396

Bennoun P (1982) Evidence for a respiratory chain in the chloroplast. Proc Natl Acad Sci USA 79: 4352-4356

Bertsch WF, Azzi JR (1965) A relative maximum in the decay of long-term delayed light emission from the photosynthetic apparatus. Biochim Biophys Acta 94: 15-26

Betti M, Arcondéguy T, Márquez AJ (2006) Molecular analysis of two mutants from Lotus japonicus deficient in plastidic glutamine synthetase: functional properties of purified GLN2 enzymes. Planta 224: 1068-1079

Betti M, García-Calderón M, Pérez-Delgado CM, Credali A, Estivill G, Galván F, Vega JM, Márquez AJ (2012) Glutamine synthetase in legumes: recent advances in enzyme structure and functional genomics. Int J Mol Sci 13: 7994-8024

Betti M, García-Calderón M, Pérez-Delgado CM, Credali A, Pal'ove-Balang P, Estivill G, Repčák M, Vega JM, Galván F, Márquez AJ (2014) Reassimilation of ammonium in Lotus japonicus. J Exp Bot 65: 5557-5566

Bürling K, Ducruet J-M, Cornic G, Hunsche M, Cerovic ZG (2014) Assessment of photosystem II thermoluminescence as a tool to invetigate the effects of dehydration and rehydration on the cyclic/chlororespiratory electron pathways in wheat and barley leaves. Plant Sci 223: 116-123

Demeter S, Govindjee (1989) Thermoluminescence in plants. Physiol Plant 75: 121-130

Ducruet JM (2003) Chlorophyll thermoluminescence of leaf discs: simple instruments and progress in signal interpretation open the way to new ecophysiological indicators. J Exp Bot 54: 2419-2430

Ducruet J-M, Vass I (2009) Thermoluminescence: experimental. Photosynth Res 101: 195-204

Ducruet JM, Vavilin D (1999) Chlorophyll high-temperature thermoluminescence emission as an indicator of oxidative stress: perturbating effects of oxygen and leaf water content. Free Radic Res 31: 187-192

Farmer EE, Mueller MJ (2013) ROS-mediated lipid peroxidation and RES-activated signaling. Annu Rev Plant Biol 64: 429-450

Garab G, Lajkó F, Mustárdy L, Márton L (1989) Respiratory control over photosynthetic electron transport in chloroplasts of higher-plant cells: evidence for chlororespiration. Planta 179: 349-358

García-Calderón M, Chiurazzi M, Espuny MR, Márquez AJ (2012) Photorespiratory metabolism and nodule function: behavior of Lotus japonicus mutants deficient in plastid glutamine synthetase. Mol Plant Microbe Interact 25: 211-219

Gerst U, Schönknecht G, Heber U (1994) ATP and $\mathrm{NADPH}$ as the driving force of carbon reduction in leaves in relation to thylakoid energization by light. Planta 193: $421-429$

Guerrero F, Zurita JL, Roncel M, Kirilovsky D, Ortega JM (2014) The role of the high potential form of the cytochrome b559: study of Thermosynechococcus elongatus mutants. Biochim Biophys Acta 1837: 908-919

Hagemann M, Weber APM, Eisenhut M (2016) Photorespiration: origins and metabolic integration in interacting compartments. J Exp Bot 67: 2915-2918

Handberg K, Stougaard J (1992) Lotus japonicus, an autogamous, diploid legume species for classical and molecular genetics. Plant J 2: 487-496

Havaux M (1996) Short-term responses of photosystem I to heat stress. Photosynth Res 47: 85-97

Havaux M, Niyogi KK (1999) The violaxanthin cycle protects plants from photooxidative damage by more than one mechanism. Proc Natl Acad Sci USA 96: $8762-8767$

Havaux M, Rumeau D, Ducruet JM (2005) Probing the $\mathrm{FQR}$ and $\mathrm{NDH}$ activities involved in cyclic electron transport around photosystem I by the 'afterglow' luminescence. Biochim Biophys Acta 1709: 203-213

Heber U, Neimanis S, Dietz KJ, Viil J (1986) Assimilatory power as a driving force in photosynthesis. Biochim Biophys Acta 852: 144-155

Husted S, Mattsson M, Möllers C, Wallbraun M, Schjoerring JK (2002) Photorespiratory $\mathrm{NH}_{4}{ }^{+}$production in leaves of wild-type and glutamine synthetase 2 antisense oilseed rape. Plant Physiol 130: 989-998

Johnson GN, Boussac A, Rutherford AW (1994) The origin of $40-50^{\circ} \mathrm{C}$ thermoluminescence bands. Biochim Biophys Acta 1184: 85-92

Keys AJ (2006) The re-assimilation of ammonia produced by photorespiration and the nitrogen economy of $\mathrm{C} 3$ higher plants. Photosynth Res 87: 165-175

Kozaki A, Takeba G (1996) Photorespiration protects C3 plants from photooxidation. Nature 384: 557-560

Krieger A, Bolte S, Dietz K-J, Ducruet J-M (1998) Thermoluminescence studies on the facultative crassulacean-acid- metabolism plant Mesembryanthemum crystallinum L. Planta 205: 587-594 
Lintala M, Allahverdiyeva Y, Kangasjärvi S, Lehtimäki N, Keränen M, Rintamäki E, Aro EM, Mulo P (2009)

Comparative analysis of leaf-type ferredoxin-NADP ${ }^{+}$ oxidoreductase isoforms in Arabidopsis thaliana. Plant J

57: 1103-1115

Márquez AJ, Betti M, García-Calderón M, Pal'ove-Balang P, Díaz P, Monza J (2005) Nitrate assimilation in Lotus japonicus. J Exp Bot 56: 1741-1749

Maurino VG, Peterhansel C (2010) Photorespiration: current status and approaches for metabolic engineering. Curr Opin Plant Biol 13: 248-255

Mellvig S, Tillberg J-E (1986) Transient peaks in the delayed luminescence from Scenedesmus obtusiusculus induced by phosphorus starvation and carbon dioxide deficiency. Physiol Plant 68: 180-188

Messant M, Timm T, Fantuzzi A, Weckwerth W, Bauwe $H$, Rutherford A, AW K-LA (2018) Glycolate induces redox tuning of photosystem II in vivo: study of a photorespiration mutant. Plant Physiol 177: 1277-1285

Miranda T, Ducruet J (1995) Characterization of the chlorophyll thermoluminescence afterglow in dark-adapted or far-red-illuminated plant leaves. Plant Physiol Biochem 33: 689-699

Nakamoto H, Sundblad L-G, Gardeström P, Sundbom E (1988) Far-red stimulated long-lived luminescence from barley protoplasts. Plant Sci 55: 1-7

Orea A, Pajuelo P, Pajuelo E, Quidiello C, Romero JM, Márquez AJ (2002) Isolation of photorespiratory mutants from Lotus japonicus deficient in glutamine synthetase. Physiol Plant 115: 352-361

Palmqvist K, Sundblad L-G, Samuelsson G, Sundbom E (1986) A correlation between changes in luminescence decay kinetics and the appearance of a $\mathrm{CO}_{2}$-accumulating mechanism in Scenedesmus obliquus. Photosynth Res 10: 113-123

Pérez-Delgado CM, García-Calderón M, Sánchez DH, Udvardi MK, Kopka J, Márquez AJ, Betti M (2013) Transcriptomic and metabolic changes associated with photorespiratory ammonium accumulation in the model legume Lotus japonicus. Plant Physiol 162: 1834-1848

Pérez-Delgado CM, García-Calderón M, Máerquez AJ, Betti M (2015) Reassimilation of photorespiratory ammonium in Lotus japonicus plants deficient in plastidic glutamine synthetase. PLoS One 10: e0130438

Pérez-Delgado CM, Moyano TC, García-Calderón M, Canales J, Gutiérrez RA, Márquez AJ, Betti M (2016) Use of transcriptomics and co-expression networks to analyze the interconnections between nitrogen assimilation and photorespiratory metabolism. J Exp Bot 67: 3095-3108

Peterhansel C, Horst I, Niessen M, Blume C, Kebeish R, Kürkcüoglu S, Kreuzaler F (2010) Photorespiration. The Arabidopsis book. American Society of Plant Biologists 8: e0130
Repetto G, Zurita JL, Roncel M, Ortega JM (2015) Thermoluminescence as a complementary technique for the toxicological evaluation of chemicals in photosynthetic organisms. Aquat Toxicol 158: 88-97

Roman M, Ducruet J-M (2000) Evidence from leaf thermoluminescence for a decrease of the [NADPH + ATP] energetic potential in cold-sensitive Pisum sativum L. varieties upon hardening at $5^{\circ} \mathrm{C}$. J Plant Physiol 157: 177-181

Roncel M, Ortega JM (2005) Afterglow thermoluminescence band as a possible early indicator of changes in the photosynthetic electron transport in leaves. Photosynth Res 84: 167-172

Roncel M, Yruela I, Kirilovsky D, Guerrero F, Alfonso M, Picorel R, Ortega JM (2007) Changes in photosynthetic electron transfer and state transitions in an herbicide-resistant D1 mutant from soybean cell cultures. Biochim Biophys Acta 1767: 694-702

Roncel M, González-Rodríguez A, Naranjo B, Bernal-Bayard P, Lindahl A, H M, Navarro J, Ortega J (2016) Iron deficiency induces a partial inhibition of the photosynthetic electron transport and a high sensitivity to light in the diatom Phaeodactylum tricornutum. Front Plant Sci 7: 1050

Rutherford AW, Crofts AR, Inoue Y (1982) Thermoluminescence as a probe of Photosystem II photochemistry. The origin of the flash-induced glow peaks. Biochim Biophys Acta 682: 457-465

Sajnani C, Zurita JL, Roncel M, Ortega JM, Barón M, Ducruet JM (2007) Changes in photosynthetic metabolism induced by tobamovirus infection in Nicotiana benthamiana studied in vivo by thermoluminescence. New Phytol 175: 120-130

Sundblad L-G, Palmqvist K, Samuelsson G (1986) Luminescence decay kinetics in relation to the relaxation of the transthylakoid $\Delta \mathrm{pH}$ from high and low $\mathrm{CO}_{2}$ adapted cells of Scenedesmus obliquus. FEBS Lett 209: $28-32$

Sundblad L-G, Schröder WP, kerlund H-E (1988) S-state distribution and redox state of $\mathrm{Q}_{\mathrm{A}}$ in barley in relation to luminescence decay kinetics. Biochim Biophys Acta 973: $47-52$

Takahashi S, Badger MR (2011) Photoprotection in plants: a new light on photosystem II damage. Trends Plant Sci 16: $53-60$

Takahashi S, Bauwe H, Badger M (2007) Impairment of the photorespiratory pathway accelerates photoinhibition of Photosystem II by suppression of repair but not acceleration of damage processes in Arabidopsis. Plant Physiol 144: 487-494

Triantaphylidès C, Krischke $M$, Hoeberichts FA, Ksas B, Gresser G, Havaux M, Van Breusegem F, Mueller MJ (2008) Singlet oxygen is the major reactive oxygen species involved in photooxidative damage to plants. Plant Physiol 148: 960-968 
Urban O (2003) Physiological impacts of elevated $\mathrm{CO}_{2}$ concentration ranging from molecular to whole plant responses. Photosynthetica 41: 9-20

Vavilin DV, Ducruet J-M (1998) The origin of $115-130^{\circ} \mathrm{C}$ thermoluminescence bands in chlorophyll-containing material. Photochem Photobiol 68: 191-198

Vavilin DV, Matorin DN, Rubin AB (2002)

High-temperature thermoluminescence of chlorophyll as a method to study lipid peroxidation in planktonic algae. Arch Hydrobiol 153: 685-701

Wallsgrove RM, Turner JC, Hall NP, Kendall AC, Bright SWJ (1987) Barley mutants lacking chloroplast glutamine synthetase - biochemical and genetic analysis. Plant Physiol 83: 155-158
Wingler A, Lea PJ, Quick WP, Leegood RC (2000) Photorespiration: metabolic pathways and their role in stress protection. Philos Trans R Soc Lond B Biol Sci 355: 1517-1529

Woodall J, Forde BG (1996) Glutamine synthetase polypeptides in the roots of 55 legume species in relation to their climatic origin and the partitioning of nitrate assimilation. Plant Cell Environ 19: $848-858$

Zurita JL, Roncel M, Aguilar M, Ortega JM (2005) A thermoluminescence study of Photosystem II back electron transfer reactions in rice leaves - effects of salt stress. Photosynth Res 84: 131-137 